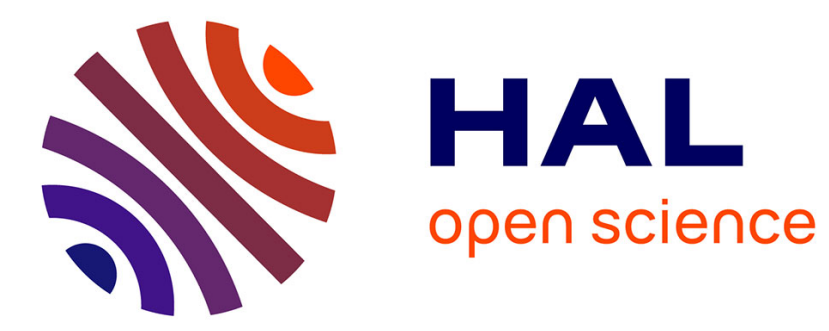

\title{
Numerical simulation of workpiece thermal field in drilling CFRP/Aluminum alloy
}

Maxime Montoya, Madalina Calamaz, Daniel Gehin, Franck Girot

\section{To cite this version:}

Maxime Montoya, Madalina Calamaz, Daniel Gehin, Franck Girot. Numerical simulation of workpiece thermal field in drilling CFRP/Aluminum alloy. Key Engineering Materials, 2014, 611-612, pp.12261235. 10.4028/www.scientific.net/KEM.611-612.1226 . hal-01203182

\section{HAL Id: hal-01203182 \\ https://hal.science/hal-01203182}

Submitted on 22 Sep 2015

HAL is a multi-disciplinary open access archive for the deposit and dissemination of scientific research documents, whether they are published or not. The documents may come from teaching and research institutions in France or abroad, or from public or private research centers.
L'archive ouverte pluridisciplinaire HAL, est destinée au dépôt et à la diffusion de documents scientifiques de niveau recherche, publiés ou non, émanant des établissements d'enseignement et de recherche français ou étrangers, des laboratoires publics ou privés. 


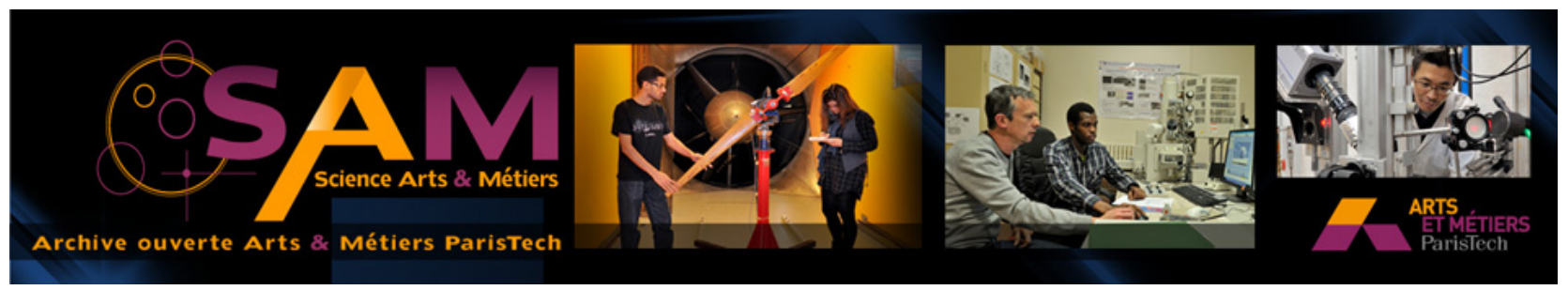

\section{Science Arts \& Métiers (SAM)}

is an open access repository that collects the work of Arts et Métiers ParisTech researchers and makes it freely available over the web where possible.

This is an author-deposited version published in: http://sam.ensam.eu

Handle ID: .http://hdl.handle.net/10985/10102

\section{To cite this version :}

MAXIME MONTOYA, Madalina CALAMAZ, DANIEL GEHIN, FRANCK GIROT - Numerical simulation of workpiece thermal field in drilling CFRP/Aluminum alloy - Key Engineering Materials - Vol. 611-612, p.1226-1235 - 2014 


\title{
Numerical simulation of workpiece thermal field in drilling CFRPIAluminum alloy
}

\author{
Maxime Montoya ${ }^{1}$, Madalina Calamaz ${ }^{1}$, Daniel Gehin ${ }^{1}$ and Franck Girot ${ }^{1,2}$ \\ ${ }^{1}$ Arts et Métiers ParisTech, I2M, UMR 5295, F-33400 Talence, France, \\ ${ }^{2}$ Department of Mechanical Engineering, ETSIB, University of the Basque Country, Bilbao, Spain.
}

Keywords: FEM simulation, temperature field, drilling, CFRP/Al or Ti stacks.

\begin{abstract}
Machining is a process implying extremely high coupled thermo-mechanical stresses. The workpiece mechanical properties decrease with the temperature generated during the process and that temperature has a direct influence on wear intensity undergone by the tool. In the case of a drilling operation, the temperature generated by the cutting process can lead to metal burr formation and/or composite matrix degradation by burning. When these two materials are used in the form of a sandwich-type stacking, the temperature attained in the metallic part can cause new defects such as: i) a difference between the diameters measured in each material and ii) organic matrix damages due to heat diffusion from the metal towards the CFRP layer.

Temperature reached at the tool/workpiece interface is difficult to measure during drilling operation, due to its enclosed configuration; numerical simulation is therefore a good alternative to access to this information. The purpose of this study is to develop and carry out numerical simulations in order to estimate the workpiece thermal field generated during drilling. The simulations are validated by comparing simulated and measured temperatures at $4 \mathrm{~mm}$ from the holes wall. This method is applied to evaluate thermal field generated during drilling (with chip removing cycles) of CFRP/Aluminum alloy stacks. The influence of the drilling kinematics on the workpiece thermal field is also investigated.
\end{abstract}

\section{Introduction}

Due to their high strength to weight ratio [1-3], hybrid structures made of carbon fibre reinforced plastic (CFRP) combined with metal, often aluminum (Al) or titanium (Ti) alloys, have become widely used in fields such as aeronautics or aerospace. The parts produced in these fields are usually assembled by bolting or riveting. This assembly technique requires a prior drilling operation. In the case of multi-material parts, drilling must be done in one shot, in order to lead to a good hole positioning accuracy.

Few publications have been focused on the multi-materials drilling process. In 2001, Ramulu and al. [1] published one of the first studies on drilling of multi-material stacks (graphite/bismaleimidetitanium alloy). Their work has shown that delamination is one of the main problems in multi material drilling. The best stack sequence to minimize this defect was found to be CFRP on the top and metal on the bottom. The authors also noted that thermal damages can be seen on the composite layer due to the heat generated during the process.

These observations were supplemented by a study on drilling of multi-layer materials, which consist in CFRP, titanium and aluminum alloys, carried out by Brinksmeier et al. [4]. The influence of coatings and tool geometry on tool wear, forces, holes quality and chip formation has been analysed in their study. The main problems occurred in multi-material drilling were highlighted: CFRP delamination, tearing and damage on the hole entry, burr formation, intensive tool wear and a difference between diameters measured in each material. 
A lot of these problems, as the CFRP delamination and fiber tearing on the hole wall [5-7], thermal damage [8-10] and burr formation [11;12] are inherent to the drilling process for each material taken separately. Only intensive wear, differences between diameters measured in each material, CFRP damage on the hole entry and CFRP thermal damage are inherent to the multi-material drilling operations.

The metallic chips outgoing from CFRP hole can damage the hole entry as stated by Zitoune et al. [13] and Brinksmeier et al. [4]. The formation of this type of damage was observed and described by Montoya et al. [14] in a study on CFRP/Al and CFRP/Ti drilling. During drill rotation, depending on the orientation between metallic chip edge and the carbon fibers, metallic chips can fit between the carbon fibers of the CFRP first ply and pull them out. Studies on diameters differences highlighted a lot of diameter configurations. In the case of CFRP/Al stacks, smaller diameter values have been found in the CFRP-part than in the aluminum part, by Brinksemier et al. [4] and Zitoune et al. [13]. First authors have assigned it to the low CFRP modulus of elasticity; the last have considered the elastic stresses relaxation during machining as being the reason. The opposite trend can also be observed: smaller hole diameter values in the aluminum part than in the CFRP-part. As for the roughness and the damage at the CFRP hole entry, the metallic chips can enlarge the CFRP hole when they are discharged. When the drilling process is carried out with a chip removing cycle, the enlargement of the CFRP hole can also be due to the multi passages of the tool on the hole wall surface. This phenomenon was observed by Montoya [15]. The heat generated during the drilling process can also lead to a thermal damage of the CFRP matrix as observed by Ramulu et al. [1].

To justify the intensive wear, the diameter difference and the CFRP thermal damage observed during the drilling of multi-material, the generated workpiece thermal field must be known. Drilling is a process that has a confined configuration. Therefore, it is difficult to access, experimentally, to this information. Nevertheless, combining experimental measurements with numerical simulations is a good alternative to obtain the workpiece thermal field. This article proposes a new method to estimate the thermal field in the workpiece during a drilling operation. The method accuracy is evaluated on the drilling of CFRP and aluminum alloy stacks with a chip removing cycle. The location of the maximum temperature on the interface tool/workpiece is discussed. The influence of the drilling kinematics on the attained maximum temperature is also investigated.

\section{Numerical model}

The objective of the current approach is to obtain an estimation of the temperature generated on the wall of the drilled hole, using temperature measurements collected $4 \mathrm{~mm}$ from this wall. A numerical simulation was carried out in order to simulate the application and the movement of the heat flux on the hole wall. This simulation is validated by comparing numerical temperatures with the measured ones (at $4 \mathrm{~mm}$ from the hole wall). Once validated, the numerical model enables to obtain temperature on the hole wall and therefore the maximum temperature generated by drilling. The software chose for simulations is COMSOL Multiphysics, a software based on finite elements method, able to take into account thermal loadings in both steady-state and transient conditions. The heat transfer by conduction is governed by thermal equation whose formulation is as follows:

$\rho \cdot C p \cdot \frac{\partial T}{\partial t}-\nabla \cdot(k \nabla T)=Q$

Where :

$\begin{array}{ll}\rho & \text { density }\left(\mathrm{kg} / \mathrm{m}^{3}\right) ; \\ \mathrm{Cp} & \text { specific heat }(\mathrm{J} /(\mathrm{kgK})) ; \\ \mathrm{T} & \text { temperature }(\mathrm{K}) ; \\ \mathrm{k} & \text { thermo-conductivity; } \\ \mathrm{Q} & \text { heat sources. }\end{array}$

In the case of anisotropic materials such as composites, $\mathrm{k}$ becomes a tensor as below 


$$
k=\left[\begin{array}{lll}
k_{x x} & k_{x y} & k_{x z} \\
k_{y x} & k_{y y} & k_{y z} \\
k_{z x} & k_{z y} & k_{z z}
\end{array}\right]
$$

In drilling, workpiece surfaces are subjected to heat sources as well as convective heat exchange due to lubrication. These boundary conditions are simulated by the application of a heat flux to the affected area. This heat flux is expressed by the following relation:

$$
k \nabla T=q_{0}+h\left(T_{\text {inf }}-T\right)
$$

Where :

$$
\begin{array}{ll}
q_{0} & \text { density of heat flow within the scope }\left(\mathrm{W} / \mathrm{m}^{2}\right) \\
h & \text { coefficient of convective transfer }\left(\mathrm{W} / \mathrm{Km}^{2}\right) ; \\
T & \text { surface temperature }(\mathrm{K}) ; \\
T_{\text {inf }} & \text { ambient temperature of the environment }(\mathrm{K}) .
\end{array}
$$

In order to correctly describe the heat flux application, it is necessary that the time step between two calculations be smaller than the lowest time of application of different considered heat flux. In this study, the maximum time step is considered as $10^{\text {th }}$ part of the time required to achieve a pass of $3 \mathrm{~mm}$ at the feed speed Vf $(120 \mathrm{~mm} / \mathrm{mn})$.

\begin{tabular}{|c|c|c|c|c|}
\hline \multicolumn{2}{|c|}{ Stacking } & \multicolumn{2}{|c|}{ CFRP/Al } & \\
\hline \multirow[b]{2}{*}{ Plate 1} & Composition & \multirow{2}{*}{\multicolumn{2}{|c|}{$\begin{array}{c}\text { Carbon } \\
\text { T800_DA550 } \\
7 \mathrm{~mm}\end{array}$}} & \\
\hline & Thickness & & & \\
\hline \multirow[b]{2}{*}{ Plate 2} & Composition & \multirow{2}{*}{\multicolumn{2}{|c|}{$\begin{array}{c}\text { Aluminum } \\
7010 \\
14 \mathrm{~mm} \\
\end{array}$}} & \\
\hline & Thickness & & & \\
\hline & \multicolumn{3}{|l|}{ a) } & \\
\hline & \multirow{2}{*}{ Unit } & \multicolumn{2}{|c|}{ CFRP } & 7010 \\
\hline & & Radial & Axial & \\
\hline $\begin{array}{c}\text { Thermal } \\
\text { conductivity }\end{array}$ & {$[\mathrm{W} /(\mathrm{m} * \mathrm{~K})]$} & 3.4 & 0.8 & 157 \\
\hline Specific heat & {$\left[\mathrm{W} /\left(\mathrm{kg}^{*} \mathrm{~K}\right)\right]$} & \multicolumn{2}{|c|}{980} & 860 \\
\hline Density & {$\left[\mathrm{kg} / \mathrm{m}^{3}\right]$} & \multicolumn{2}{|c|}{1550} & 2830 \\
\hline
\end{tabular}

The modeled machining operation is drilling $6 \mathrm{~mm}$ diameter holes in two stacked materials witch are stuck by a metallic adhesive. The composition of the two plates and their thermal characteristics are shown in Table 1. Thermal properties of the CFRP used in this study were measured by flash method by the Laboratory for Thermosctructural Composites.

Table 1. a) Stack composition and b) characteristics of materials

b)

The surface, on which the heat flux generated by cutting is applied, can be considered of revolution. This assumption simplifies the problem to a $2 \mathrm{D}$ axisymmetric case. The software does not enable to change the workpiece geometry during cutting simulation; thus, the removal of the material beneath the drill cannot be simulated. Therefore, the application area of the heat flux generated on the cutting edge is considered cylindrical. The workpiece width is $60 \mathrm{~mm}$, in order to avoid edge effects on surface S4 (Figure 1.a). On a width of $10 \mathrm{~mm}$ from the $\mathrm{z}$ axis, the mesh is as thin as possible due to high temperature gradients occurred in this area. Far from this interest zone, the chosen mesh is coarser. Two measuring points have been set in order to model the location of the two thermocouples used to perform the experimental measurements. Along the $\mathrm{z}$ axis, they are put at mid-thickness of each material. Their radial position comes from the measurement of the actual distance between the hole wall and the center of the thermocouple housing, for each concerned test. This measurement was carried out using a digital microscope KEYENCE (see Figure 1.b). 


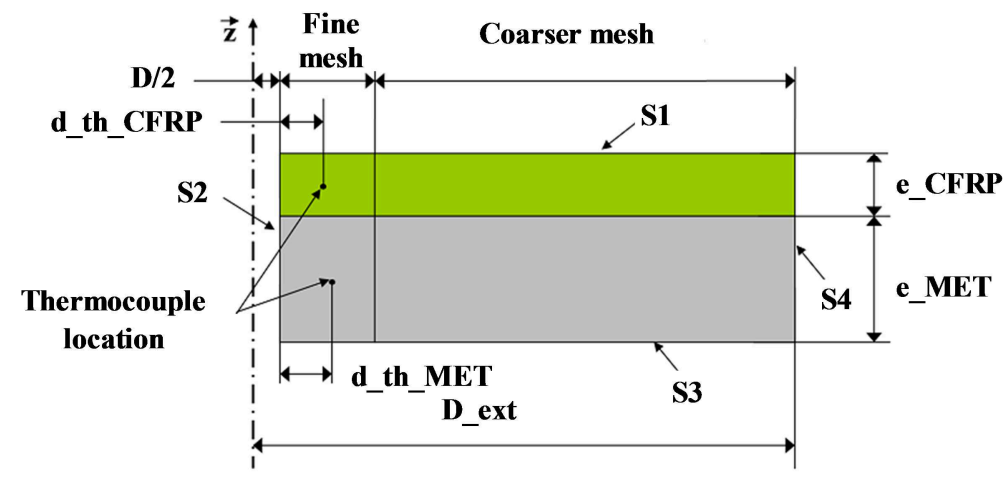

a)

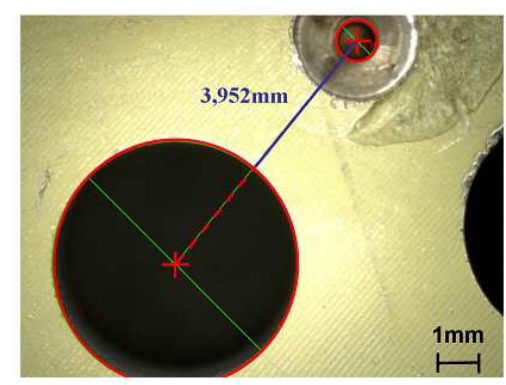

b)

Figure 1. a) Model set of the workpiece, b) measuring the distance between the hole wall and the center of the thermocouple housing.

Where :
$\mathrm{D}$
diameter of the drilled hole;
D ext
outer diameter of the specimen;
e CFRP
thickness of the composite part;
e_MET
thickness of the metal part;
d_th_CFRP distance between the hole wall and the center of the thermocouple housing in the composite;
d_th_MET distance between the hole wall and the center of the thermocouple housing in the metal.

\section{Heat flux modeling}

Two distinct heat flux can be observed during a drilling operation; i) the heat flux generated by cutting, located on the tool cutting edge; ii) the flux generated by friction between the drill margins and the hole wall. Bono et al. [17] as well as Cardoso et al. [18] have shown that the heat flux generated by the tool edges is higher on the drill corner than on its point. The distribution of the heat flux produced by the drill cutting edges can be considered triangular, as shown in Figure 1. The heat flux generated by the cutting edge will be applied on the height of the cutting edge (h_cutting) and will have a triangular distribution. The maximum flux transferred to the hole wall will therefore be localized on the corner of the drill bit (Figure 1). Because of the chip removing cycle, the friction of the drill margin on the hole wall is applied during drilling and while the drill plunge again, between two pass of cutting. Due to its back taper, the drill bit is not in contact with the hole wall over the entire margin length. The analysis of torque generated during machining and observations using an electronic microscope have enabled to highlight the contact length between drill margin and hole wall; this contact length is noted $\mathrm{h}$ _friction in Figure 1.

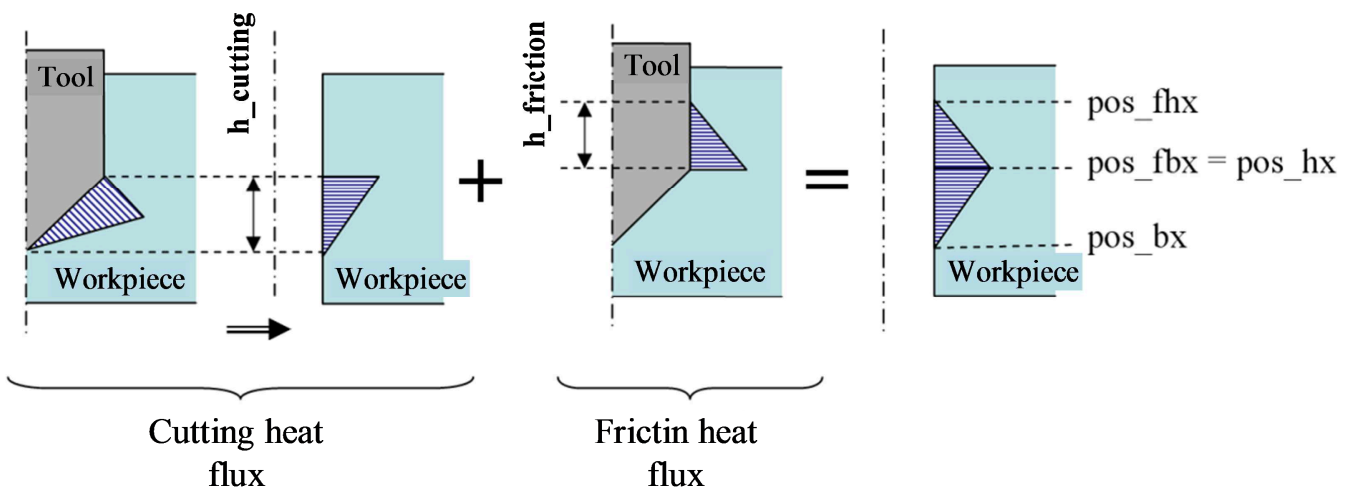

Figure 1. : Modelling of the heat flow generated by the cutting and the friction between the tool margin and the hole wall 
As defined by Bonnet [16], the heat flux generated by friction is proportional to tangential stress on the surface of the drill margin:

$\varphi=\sigma_{\mathrm{t}} \cdot \mathrm{Vc} \cdot \beta$

Where:
$\varphi$
$\sigma_{\mathrm{t}}$
$\mathrm{Vc}$
$\beta$
heat flux density received by a margin $\left(\mathrm{W} / \mathrm{mm}^{2}\right)$;
shear stress on a margin $\left(\mathrm{N} / \mathrm{mm}^{2}\right)$;
sliding speed or cutting speed $(\mathrm{m} / \mathrm{s})$;
partition coefficient of the heat flux at the interface.

A preliminary numerical simulation has highlighted that certain temperatures increase in the CFRP are not related to cutting or friction (see blue curve in Figure 2). These temperature rises always occur after a cutting pass in the metal part. As seen in Figure 2 (red curve), these temperature rises are not shown by the result of the preliminary simulation, which only takes into account the heat flux generated by cutting and friction; they either cannot be the result of the heat diffusion produced during metal cutting into CFRP part. It is also possible to see in Figure 2 that the time between the cutting phase and these temperature rises does not change. These ones can only be attributed to heat transmission due to the contact between hot metal chips and the hole wall. The metal chips need only few milliseconds to go out from the hole; thus, the chip temperatures when it is formed and it comes out of the hole, are considered similar. Therefore, the intensity of the corresponding heat flux is identical over the entire height of the composite hole wall.

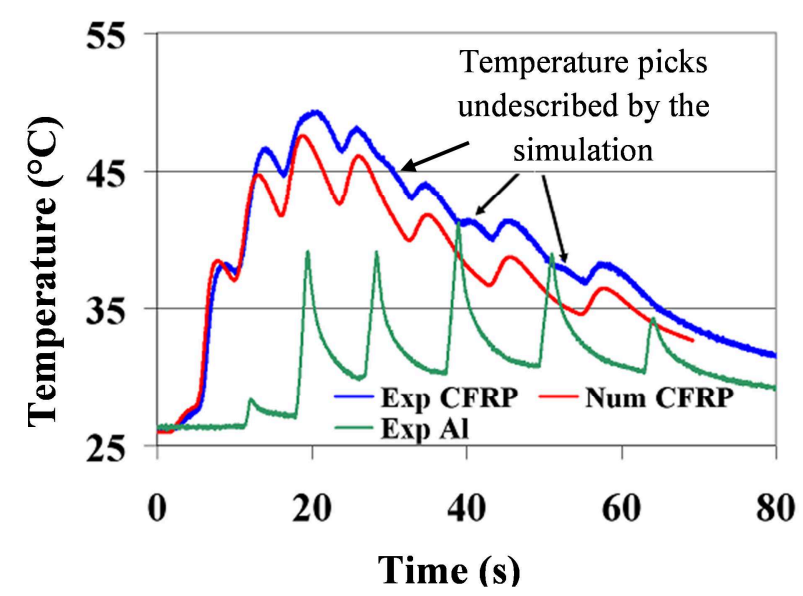

Figure 2. Comparison between experimental and numerical results (only heat flux related to cutting and friction are taken into account).

\section{Heat flux kinematics}

In order to correctly program the sequencing of different heat flux and thermal exchanges during drilling, it is essential to know the times between the end of a cutting pass $i$ and the beginning of the following cutting pass $j$. These times are noted with t_retour_i_j. Figure 3 shows the cutting forces registered during drilling of a CFRP/Aluminum alloy stack. From these experimental results it is possible to extract the time t_retour_ijj. 


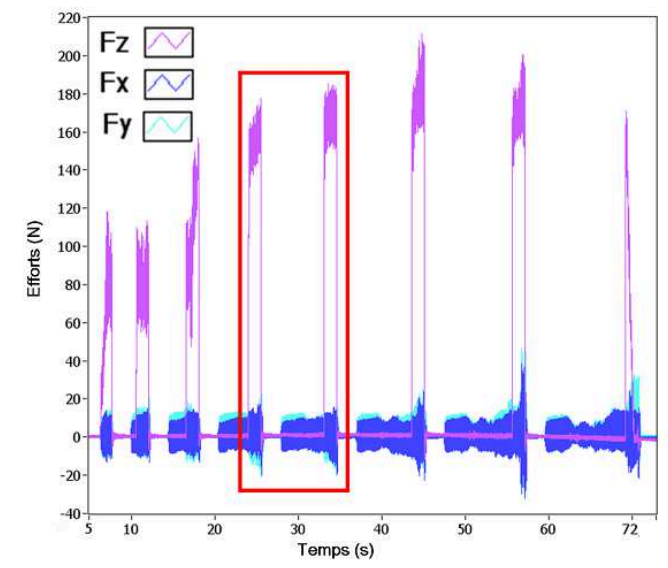

(a)

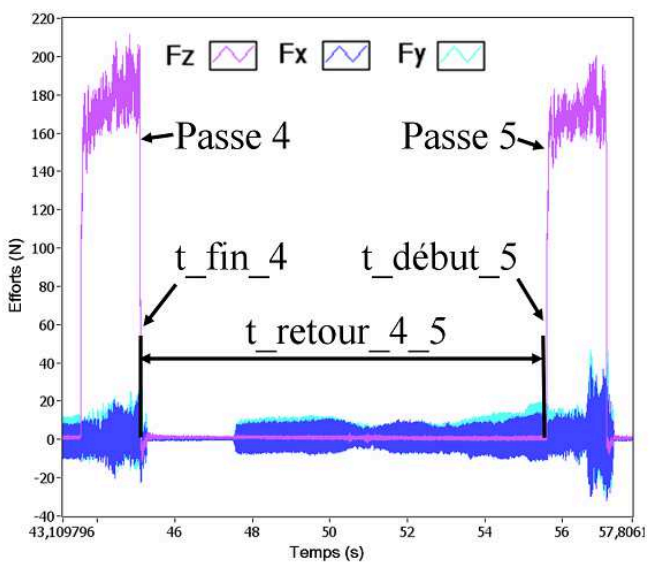

(b)

Figure 3. (a) Cutting forces during drilling of CFRP/Aluminium alloy stack; (b) determination of return times t_retour_i_j.

From the back time and the displacement time of the drill bit the beginning and the end of each heat flux application can be calculated. The simulation includes four heat flux and interface transfers that are activated and inactivated during cutting. The convection (due to lubrication) is provided only when the drill bit does not form chips. The heat flux due to the crossing of the metal chips on the composite hole wall take place only during cutting. The heat flux generated by friction is applied during drilling and while the drill plunge again, between two pass of cutting.

\section{Estimation of the applied heat flux intensity}

Figure 4 associates each temperature rise to the heat flux that generated it. It is possible to distinguish the six temperature elevations in the aluminum corresponding to the six phases of cutting process. Resulting from one or from the superposition of several heat flux, twelve temperature increases can be observed in CFRP.

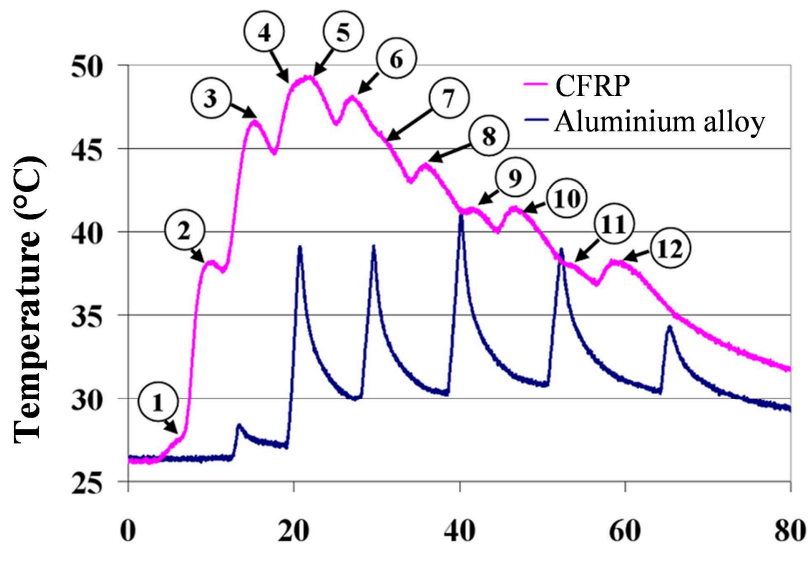

1 - Cutting and friction for pass 1

2 - Cutting and friction for pass 2

3 - Cutting, friction and chips ascent for pass 3

4 - Friction for pass 4

5 - Chips ascent for pass 4

6 - Friction for pass 5

7 - Chips ascent for pass 5

8 - Friction for pass 6

9 - Chips ascent for pass 6

10 - Friction for pass 7

11 - Chips ascent for pass 7

Time (s)

Figure 4. Temperature raises identification in the CFRP part of the multi-material.

Primary simulation revealed that the heat generated in aluminum alloy do not produce temperature rising in the composite part of the stacking. This is explained by the low temperatures reached in aluminum but also by its high thermal conductivity. The heat produced in the aluminum alloy diffuses inside itself quickly enough; this avoids affecting the CFRP part of the multi-material. Conversely, the heat generated in the CFRP produces a temperature rise of the aluminum, at the concerned measurement point. Based on the torque measured during drilling, a first heat flux 
density estimation is done. For this estimation, one considers that all the mechanical energy is converted into thermal energy and that $50 \%$ of this one is transmitted into the workpiece.

\section{Numerical results analysis}

Figure 5 shows simulation results for drilling with tools having point angles of $125^{\circ}$ (tool 1 ) and $60^{\circ}$ (tool 2). The values of applied heat flux density are detailed in Table 1.

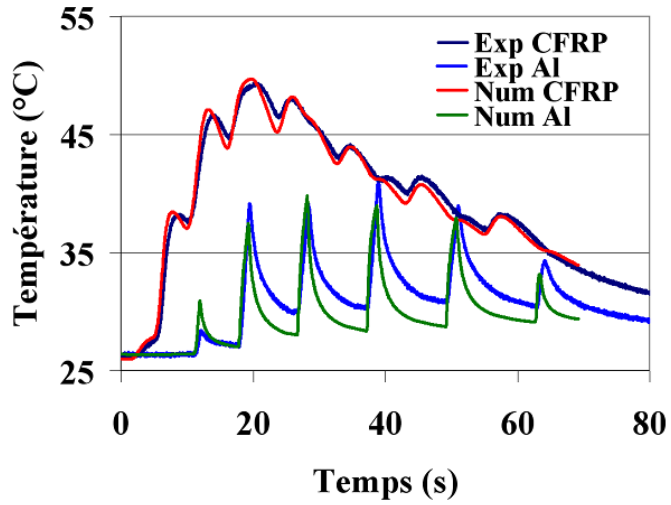

(a)

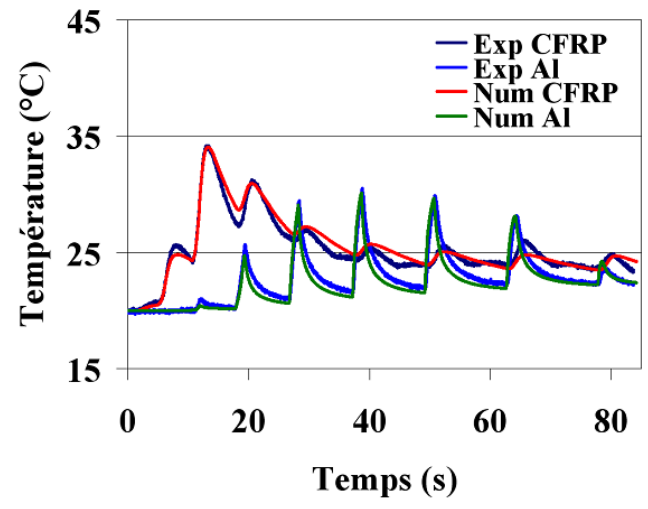

(b)

Figure 5. Comparison between experimental and numerical temperatures when using a tool having a point angle of a) $125^{\circ}$ and b) $60^{\circ}$.

Figure 5 shows that the simulations describe well the different phases of temperature rise observed experimentally. In the case of the simulation concerning tool 1 , the model enables to correctly describe the temperature rise of the CFRP as well as its cooling. The error between numerical and experimental curves is of about $3.5 \%$. For tool 2 , this error is of $8.4 \%$, the cooling phases being less well described. This different behaviour can be due to variations in the boundary conditions of the experimental test, the latter being made near one of the workpiece border. In the metallic part, the gap between the experimental and numerical curves is higher: $37 \%$ and $16 \%$ for tools 1 and 2 , respectively. The cooling phases described by numerical simulation are more accentuated than those experimentally observed.

Table 1. Summary of density heat flux $\left[\mathrm{in} \mathrm{W} / \mathrm{m}^{2}\right]$ values for the two case studies on the stack $\mathrm{CFRP} / \mathrm{Al}$

\begin{tabular}{|c|c|c|c|c|c|c|c|c|}
\hline & \multicolumn{4}{|c|}{ Tool with $125^{\circ}$ point } & \multicolumn{4}{|c|}{ Tool with $125^{\circ}$ point } \\
\hline & \multicolumn{3}{|c|}{ CFRP } & \multirow{2}{*}{$\mathrm{Al}$} & \multicolumn{3}{|c|}{ CFRP } & \multirow{2}{*}{$\mathrm{Al}$} \\
\hline Pass & Cutting & Friction & Chips & & Cutting & Friction & Chips & \\
\hline 1 & \multicolumn{2}{|c|}{$4,3 \cdot 10^{5}$} & - & - & \multicolumn{2}{|c|}{$2,8 \cdot 10^{5}$} & - & - \\
\hline 2 & \multicolumn{2}{|c|}{$4,3 \cdot 10^{5}$} & - & - & \multicolumn{2}{|c|}{$2,8 \cdot 10^{5}$} & - & - \\
\hline 3 & \multicolumn{2}{|c|}{$4,3 \cdot 10^{5}$} & $5 \cdot 10^{4}$ & $1,2 \cdot 10^{7}$ & \multirow{2}{*}{\multicolumn{2}{|c|}{$\begin{array}{l}2,8 \cdot 10^{5} \\
2,8 \cdot 10^{5}\end{array}$}} & $4 \cdot 10^{4}$ & $2,95 \cdot 10^{6}$ \\
\hline 4 & - & $3,2 \cdot 10^{5}$ & $3,75 \cdot 10^{4}$ & $1,2 \cdot 10^{7}$ & & & $4 \cdot 10^{4}$ & $2,95 \cdot 10^{6}$ \\
\hline 5 & - & $3 \cdot 10^{5}$ & $3,25 \cdot 10^{4}$ & $1,2 \cdot 10^{7}$ & - & 2,24 & $3,6 \cdot 10^{4}$ & $2,95 \cdot 10^{6}$ \\
\hline 6 & - & $2,1 \cdot 10^{5}$ & $3 \cdot 10^{4}$ & $1,2 \cdot 10^{7}$ & - & 1,4 & $3,1 \cdot 10^{4}$ & $2,95 \cdot 10^{6}$ \\
\hline 7 & - & $1,3 \cdot 10^{5}$ & $2 \cdot 10^{4}$ & $1,2 \cdot 10^{7}$ & - & 0,7 & $2,6 \cdot 10^{4}$ & $2,95 \cdot 10^{6}$ \\
\hline 8 & - & $0,8 \cdot 10^{5}$ & $1 \cdot 10^{4}$ & $1,2 \cdot 10^{7}$ & - & 0,14 & $2,6 \cdot 10^{4}$ & $2,95 \cdot 10^{6}$ \\
\hline 9 & - & - & - & - & - & 0,14 & $2,6 \cdot 10^{4}$ & $2,95 \cdot 10^{6}$ \\
\hline
\end{tabular}

The simulation results confirm the assumption that the heat flux generated by friction decreases with the number of passes of the tool on composite part. Knowing that the heat generated by friction is related to the pressure on the tool margins, these results highlighted that this friction heat decreases with the number of passes of the tool on the workpiece wall. These findings are in agreement with the hole diameter evolution in the composite part, that increases with the number of passes. 
Information about the temperature reached in each point of the workpiece during machining enables to estimate both the temperature reached on the hole wall and the extent of the heat affected areas around the drilled holes. Having access to the temperature on the hole wall enables to estimate the tool temperature in different points, these two items having a number of common features such as the tool corner and some part of the tool margins. The extent of heat affected areas gives information about the integrity of the stacking materials, an excessive temperature could damage them.

Figure 6 shows the maximum temperature reached in any point on the hole wall. The simulation shows that the maximum temperature reached in CFRP is higher $\left(160^{\circ} \mathrm{C}\right)$ than the one generated in the aluminum alloy $\left(90^{\circ} \mathrm{C}\right)$. These are the temperatures obtained during the first drilled holes. Due to tool wear, the temperature reached in CFRP exceeds $200^{\circ} \mathrm{C}$ after drilling 250 holes, with tool 1. Although this temperature is below the upper limit of the epoxy resin heat resistance $\left(350^{\circ} \mathrm{C}\right)$, this high temperature creates a risk of damaging the composite material.

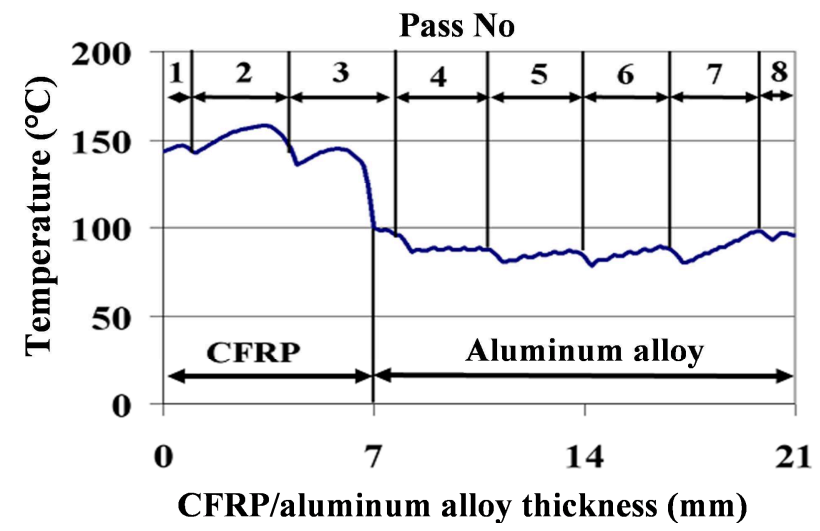

Figure 6. Maximum temperature reached on the hole wall.

Temperature changes within the same material can also be observed on the Figure 6. These variations are cyclical and can range from 10 to $70^{\circ} \mathrm{C}$, depending on the type of material being machined. Cardoso et al. [18] noticed a temperature increase with the depth of tool plunging into the hole. This temperature rise can be related to the fact that the cut does not reach a steady state. In the present study, this phenomenon being conjugated to the kinematics of the machining operation, the temperature varies cyclically. As seen in Figure 6, the minimum temperature is reached at the beginning of a cutting pass and maximum at the end of it.

The proposed simulation model also provides the extent of the heat affected area during machining. The composite area having a risk of damaging is localized near the hole wall and on a depth of $0.8 \mathrm{~mm}$ from the hole wall (see Figure 7). Thus, a depth of about $0.8 \mathrm{~mm}$ and over the entire height of the hole wall, can have a risk of burning of the composite material. 


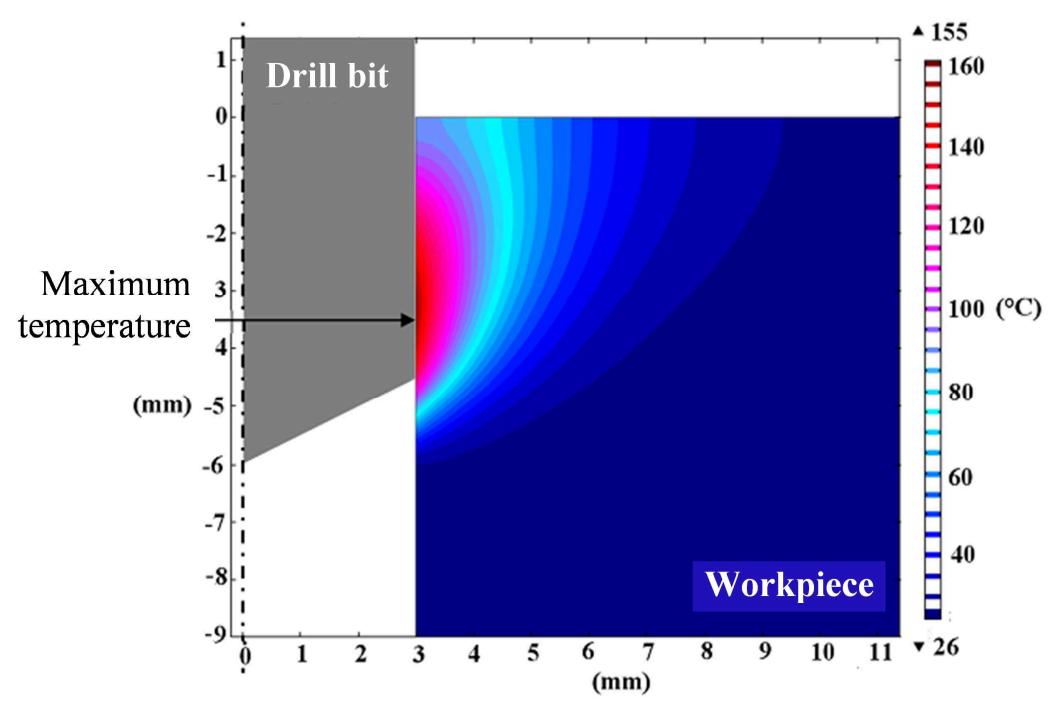

Figure 7. The position of the maximum temperature on the tool.

\section{Conclusions}

The analysis of the experimental temperature curves obtained during drilling of a CFRP/aluminium alloy stacking has shown some temperature picks that cannot be assigned to the friction and the cutting process in itself. These ones can only be attributed to heat transmission due to the contact between hot metal chips and the hole wall.

The study have shown that the heat generated in aluminum alloy do not produce temperature rising in the composite part of the stacking. This is explained by the low temperatures reached in aluminum but also by its high thermal conductivity. The heat produced in the aluminum alloy diffuses quickly enough inside itself; this avoids affecting the CFRP part of the multi-material.

The simulation revealed that the maximum temperature reached on the hole wall is generated during the passage of the heat flux associated to both cutting and friction. Temperature reached in the composite is greater than that achieved in the aluminum alloy, and that from the first drilled hole.

\section{References:}

[1] M. Ramulu, T. Branson, D. Kim, A study on the drilling of composite and titanium stacks, Composite Structures, Volume 54, Issue 1, October 2001, Pages 67-77 .

[2] R. Zitoune, V. Krishnaraj, B. S. Almabouacif, F. Collombet, M. Sima, A. Jolin. Influence of machining parameters and new nano-coated tool on drilling performance of CFRP/Aluminium sandwich. Composites Part B : Engineering, Volume 43, Issue 3, April 2012, Pages 1480-1488

[3] I.S. Shyha, S.L. Soo, D.K. Aspinwall, S. Bradley, R. Perry, P. Harden, S. Dawson. Hole quality assessment following drilling of metallic-composite stacks. International Journal of Machine Tools and Manufacture, Volume 51, Issues 7-8, July-August 2011, Pages 569-578

[4] E. Brinksmeier, R. Janssen, Drilling of Multi-Layer Composite Materials consisting of Carbon Fiber Reinforced Plastics (CFRP), Titanium and Aluminum Alloys, CIRP Annals - Manufacturing Technology, Volume 51, Issue 1, 2002, Pages 87-90.

[5] H. Hocheng, C.C Tsao, Comprehensive analysis of delamination in drilling of composite materials with various drill bits, Journal of Materials Processing Technology, Volume 140, Issues 1-3, 22 September 2003, Pages 335-339.

[6] Daniel Iliescu, Approche expérimentale et numérique de l'usinage des composites carbone/époxy, PhD Ecole Nationale Supérieure des Arts et Métiers, 2008. 
[7] R. Piquet, F. Lachaud, B. Ferret, P. Swider, Etude analytique et expérimentale du perçage de plaques minces en carbone/epoxy, vol. 1, No. 1, Mécanique et industries, Berlin : Amsterdam, 2000.

[8] I.S. Jawahir, E. Brinksmeier, R. M'Saoubi, D.K. Aspinwall, J.C. Outeiro, D. Meyer, D. Umbrello, A.D. Jayal. Surface integrity in material removal processes: Recent advances, CIRP Annals - Manufacturing Technology, Volume 60, Issue 2, 2011, Pages 603-626.

[9] D. Ulutan, T. Ozel. Machining induced surface integrity in titanium and nickel alloys: A review. International Journal of Machine Tools and Manufacture, Volume 51, Issue 3, March 2011, Pages 250-280

[10] F. Lachaud, R. Piquet, F. Collombet, L. Surcin, Drilling of composite structures, Compos. Struct. 52 (3-4) (2001) 511-516.

[11] D.A. Dornfeld, J.S. Kim, H. Dechow, J. Hewson, L.J. Chen, Drilling Burr Formation in Titanium Alloy Ti-6AI-4V, CIRP Annals - Manufacturing Technology, Volume 48, Issue 1, 1999, Pages 73-76.

[12] J.C. Aurich, D. Dornfeld, P.J. Arrazola, V. Franke, L. Leitz, S. Min, Burrs-Analysis, control and removal, CIRP Annals - Manufacturing Technology, Volume 58, Issue 2, 2009, Pages 519-542.

[13] R. Zitoune, V. Krishnaraj, B. S. Almabouacif, F. Collombet, M. Sima, A. Jolin. Influence of machining parameters and new nano-coated tool on drilling performance of CFRP/Aluminium sandwich. Composites Part B : Engineering, Volume 43, Issue 3, April 2012, Pages 1480-1488

[14] M. Montoya, M Calamaz, D Gehin, F Girot, "Evaluation of the performance of coated and uncoated carbide tools in drilling thick CFRP/aluminium alloy stacks" The International Journal of Advanced Manufacturing Technology, February 2012.

[15] M. Montoya, Optimisation du perçage d'empilages CFRP/Titane et/ou Aluminium, PhD. Ecole Nationale Supérieure des Arts et Métiers, 2013-ENAM-0019, 2013.

[16] C. Bonnet, Compréhension des mécanismes de coupe lors du perçage à sec de l'empilage Ti6Al4V/Composite fibre de carbone, thèse de l'Ecole Nationale Supérieure des Arts et Métiers, 2010.

[17] M. Bono, J. Ni. The location of the maximum temperature on the cutting edges of a drill. International Journal of Machine Tools and Manufacture, Volume 46, Issues 7-8, June 2006, Pages 901-907

[18] L. Cardoso Brandao, R. Teixeira Coelho, C.H. Lauro, Contribution to dynamic characteristics of the cutting temperature in the drilling process considering one dimension heat flow. Applied Thermal Engineering, Volume 31, Issues 17-18, December 2011, Pages 3806-3813. 